\title{
The application of activated carbon modified by ozone treatment for energy storage
}

\author{
Grzegorz Lota $^{1}$ - Piotr Krawczyk ${ }^{1} \cdot$ Katarzyna Lota $^{2}$ - Agnieszka Sierczyńska ${ }^{2}$. \\ Lukasz Kolanowski ${ }^{1} \cdot$ Marek Baraniak $^{1}$ - Tomasz Buchwald ${ }^{3}$
}

Received: 4 May 2016 / Revised: 8 June 2016 / Accepted: 13 June 2016 / Published online: 22 June 2016

(C) The Author(s) 2016. This article is published with open access at Springerlink.com

\begin{abstract}
Activated carbon modified by ozone treatment was examined. The process was carried out in a glass reactor under a continuous flow of ozone through a bed of activated carbon for $15,30,60,120$, and $240 \mathrm{~min}$. The modified and unmodified carbon materials were characterized by Raman spectroscopy and observed by scanning electron microscopy (SEM). Thermogravimetric analysis was used to estimate the presence of oxygen groups in the carbon structure. The surface area and pore size distribution were examined by nitrogen adsorption method at $77 \mathrm{~K}$. Moreover, Fourier transform infrared (FTIR) spectroscopy was used to estimate the functional groups of modified activated carbon. The carbon content was estimated using the elemental analysis. The process of ozonation increases oxygen functionalities, thus the activated carbon was tested as electrodes for an electrochemical capacitor. The performance of an electrochemical capacitor was estimated by selected alternating (AC) and direct current (DC) methods in $1 \mathrm{M} \mathrm{H}_{2} \mathrm{SO}_{4}, 1 \mathrm{M} \mathrm{Na}_{2} \mathrm{SO}_{4}$, and $6 \mathrm{M} \mathrm{KOH}$ electrolytes.
\end{abstract}

Keywords Activated carbon - Electrochemical capacitor · Ozone treatment $\cdot$ Raman spectroscopy

Grzegorz Lota

grzegorz.lota@put.poznan.pl

1 Institute of Chemistry and Technical Electrochemistry, Poznan University of Technology, Berdychowo 4, 60-965 Poznan, Poland

2 Institute of Non-Ferrous Metals Division in Poznan Central Laboratory of Batteries and Cells, Forteczna 12, 61-362 Poznan, Poland

3 Faculty of Technical Physics, Poznan University of Technology, Piotrowo 3, 60-965 Poznan, Poland

\section{Introduction}

A lot of carbonaceous materials such as biomasses (pitch, coconut shell, bamboo waste, and other agricultural waste), polymeric materials, and coal can be used as precursors for activated carbon production. Because of their outstanding properties, activated carbons (such as a high surface area, a high degree of microporosity, atoxicity, and conductivity) are widely used as, e.g., an adsorbent in water or gas purification as well as for energy storage and conversion [1-4]. The chemical and electrochemical properties of activated carbons strongly depend on the microstructure as well as the presence of functional groups on their surface. There are several methods to incorporate other heteroatoms (e.g., nitrogen, oxygen, iodine) in order to modify the carbon surface [5-10]. One method of modifying the carbon structure is oxidation by its exposure to ozone. The process of ozonation leads to an increase in the concentration of oxygen functionalities (carboxylic, carbonyl, hydroxyl, lactonic, or ether) [11, 12].

Owing to good conductivity, carbon materials are the most desirable as electrodes in electrochemical capacitors. Electrochemical capacitors (supercapacitors or ultracapacitors) are highly attractive power sources. Supercapacitors can store far more charge than conventional dielectric capacitors and have extremely high power density because of the quite fast charge/discharge cycles. Electrochemical capacitors accumulate electric charge by charging an electric double layer reversibly $[13,14]$. Scientists all around the world are faced with a great challenge of obtaining a system with high capacitance resulting in the higher energy of supercapacitors. The increase in capacitance can be reached by additional quick faradaic reactions, commonly known as pseudocapacitive effects [15-23]. In this case, pseudocapacitive effect and doublelayer capacitance both form the total capacitance of an electrochemical capacitor. It is worth mentioning that the quick 
Fig. 1 Raman spectra (a); ratio of $\mathrm{D}$ band intensity to $\mathrm{G}$ band intensity (b)
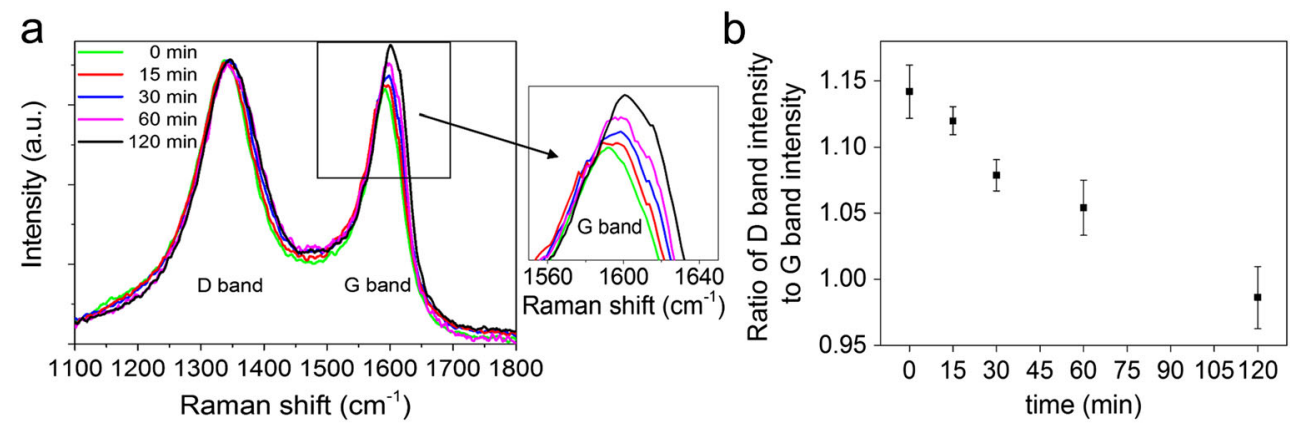

faradaic reactions at the electrode/electrolyte interface might be realized by heteroatoms (nitrogen, oxygen) being incorporated into the carbon structure. They are included in the functional groups on the surface of carbon material. Therefore, the pseudocapacitive effects can be realized by redox reactions of oxygen functionalities, for instance by the quinone/ hydroquinone $\left(\mathrm{Q} / \mathrm{QH}_{2}\right)$ redox couple $[24,25]$.

The aim of the present study was to evaluate the correlation between physicochemical changes with electrochemical properties of oxygen-doped activated carbon by ozone treatment in relation to the processes of energy storage.

\section{Experimental}

\section{Sample synthesis}

The process of ozone modification was carried out in a glass reactor under a continuous flow of ozone through a bed of activated carbon (Norit ${ }^{\circledR}$ GSX, Alfa Aesar). The constant flow rate of ozone passing was equal to $0.45 \mathrm{dm}^{3} \mathrm{~min}^{-1}$. Ozone was produced in an ozone generator supplied with air. Carbon was modified for $15,30,60,120$, and $240 \mathrm{~min}$. The reactions between activated carbon and ozone were conducted at room temperature.

\section{Sample analysis}

In order to determine the structural changes effected by ozone treatment, samples were submitted for analysis before and after they were modified using Raman spectroscopy. All the Raman spectroscopy measurements were carried out by an inVia Renishaw micro-Raman system with an argon laser, emitting $514.5 \mathrm{~nm}$ near-infrared wavelength. Functional groups of modified and raw materials were determined by Fourier transform infrared spectroscopy (Bruker model $113 \mathrm{~V}$ IR spectrometer). The morphology of samples was analyzed by scanning electron microscopy (S-3400N, Hitachi). Thermogravimetric analysis was performed on Netzsch STA 409 (NETZSCH-Gerätebau $\mathrm{GmbH}$ ). The samples were heated at the rate $5 \mathrm{~K} \mathrm{~min}^{-1}$ in argon atmosphere. The surface area as well as changes in porous texture were obtained by analysis of the nitrogen adsorption method at $77 \mathrm{~K}$ (Micromeritics ASAP 2010 volumetric adsorption system). The carbon content was estimated using the elemental analysis by means of vario MICRO cube (Elementar Analysensysteme $\mathrm{GmbH}$ ).

\section{Electrochemical measurements}

The modified and unmodified activated carbons were used as the electrode materials of an electrochemical capacitor. The electrochemical measurements were carried out using cyclic voltammetry and electrochemical impedance spectroscopy (potentiostat/galvanostat VMP3, Bio-Logic). All electrochemical studies were carried out with two- and threeelectrode cells assembled in a Swagelok ${ }^{\circledR}$ system in $1 \mathrm{M}$ $\mathrm{H}_{2} \mathrm{SO}_{4}, 1 \mathrm{M} \mathrm{Na}_{2} \mathrm{SO}_{4}$, and $6 \mathrm{M} \mathrm{KOH}$. The electrode was composed of $85 \mathrm{wt} . \%$ of carbon, $10 \mathrm{wt} . \%$ of polivinylidene fluoride (Kynar Flex 2801), and 5 wt.\% of acetylene black.

\section{Results and discussion}

Raman spectra of modified and unmodified activated carbons are presented in Fig. 1a. Two main bands can be seen which are known as the D-band and G-band. The G- and D-bands correspond to $\mathrm{sp}^{2}$ sites. The G-band is due to the bond stretching of

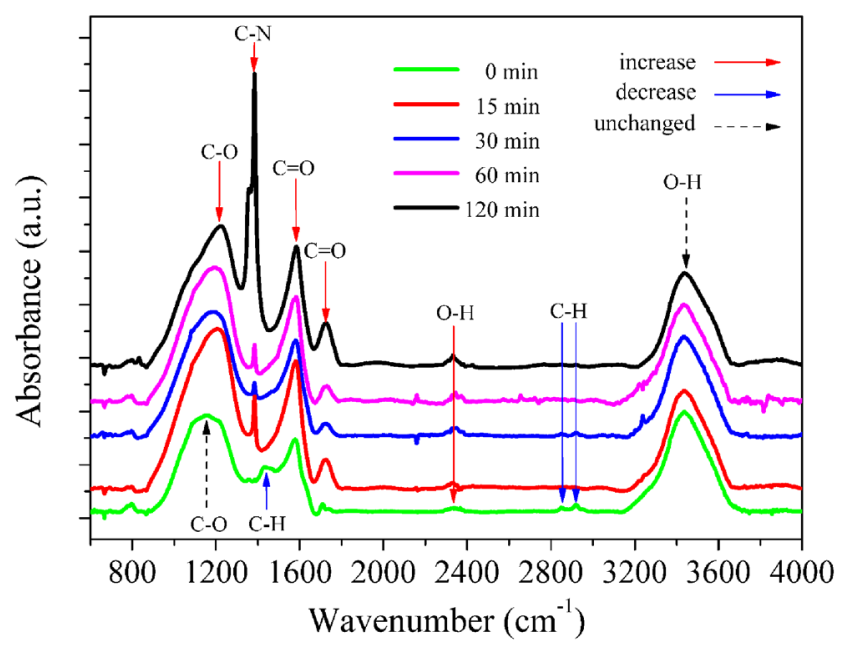

Fig. 2 FTIR spectra of pristine activated carbon and after ozone exposure 
Table 1 Results of elemental analysis

\begin{tabular}{clllll}
\hline Time of ozone exposure & C (wt.\%) & H (wt.\%) & N (wt.\%) & S (wt.\%) & O (wt.\%) by diff. \\
\hline 0 min & 87.9 & 0.4 & 0.3 & 0.3 & 11.1 \\
$15 \mathrm{~min}$ & 85.9 & 0.5 & 0.4 & 0.2 & 13.0 \\
$30 \mathrm{~min}$ & 80.9 & 0.7 & 0.8 & 0.2 & 17.5 \\
$60 \mathrm{~min}$ & 77.4 & 0.9 & 0.9 & 0.2 & 20.6 \\
$120 \mathrm{~min}$ & 72.3 & 1.1 & 1.0 & 0.2 & 25.4 \\
$240 \mathrm{~min}$ & 65.7 & 1.2 & 1.2 & 0.2 & 31.7 \\
\hline
\end{tabular}

all pairs of $\mathrm{sp}^{2}$ atoms in both rings and chains. The D-bands are thus attributed to the so-called breathing modes of $\mathrm{sp}^{2}$ atoms in rings [26]. Therefore, the D-band corresponds to the disordered carbon results from defects in graphene sheets [27]. The position of the D-band and G-band maximum were moved due to the ozonation process and were found in the region of 13391346 and $1596-1602 \mathrm{~cm}^{-1}$, respectively. The ratio of intensities of the aforementioned bands $\left(I_{D} / I_{G}\right)$ is crucial to estimate the structural disorder of carbon sheets. The $I_{D} / I_{G}$ ratio can represent the graphitization process of carbon materials. As can be seen in Fig. $1 \mathrm{~b}$, the ratio $I_{D} / I_{G}$ decreases as a function of ozonation time. The decreasing $I_{D} / I_{G}$ ratio may indicate that carbon material was partially transformed into crystalline structure [28, 29].

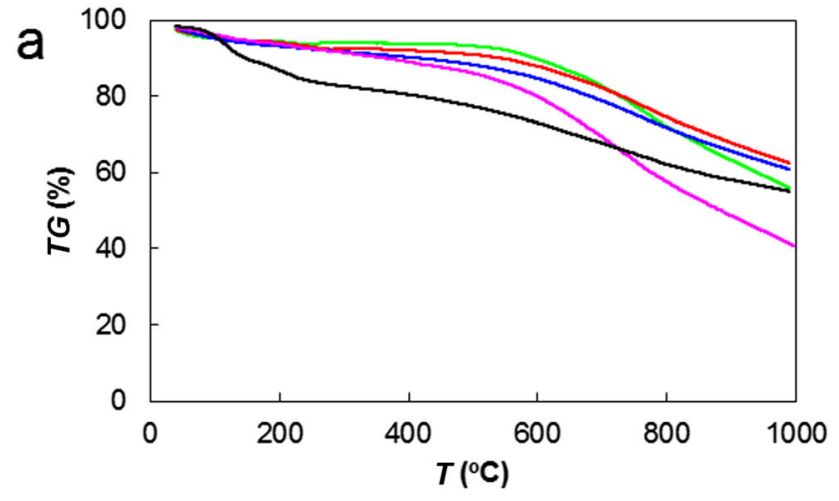

$-0 \mathrm{~min}-15 \mathrm{~min}-30 \mathrm{~min}-60 \mathrm{~min}-120 \mathrm{~min}$

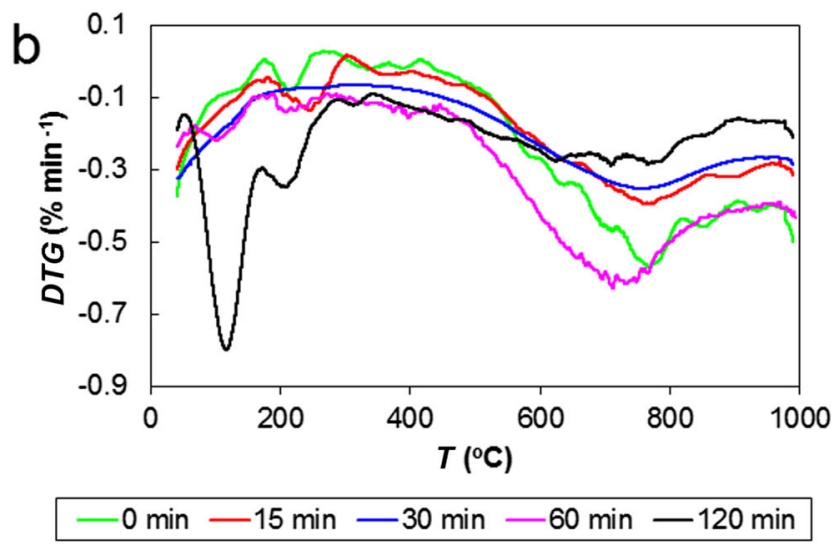

Fig. 3 Thermogravimetric analysis: mass loss versus temperature (a); derivative curve (b)
According to the three-step amorphization trajectory proposed by Ferrari and Robertson [26], the $\mathrm{sp}^{2}$ sites become converted into $\mathrm{sp}^{3}$ sites. It can be concluded that $\mathrm{sp}^{2}$ configuration is transformed from rings to chains. Due to heteroatom incorporation (nitrogen or oxygen atoms), the G-band and D-band positions move upwards to 1602 and $1346 \mathrm{~cm}^{-1}$, respectively.

FTIR measurements clearly indicate which species are present at the carbon surface before and after it was treated using
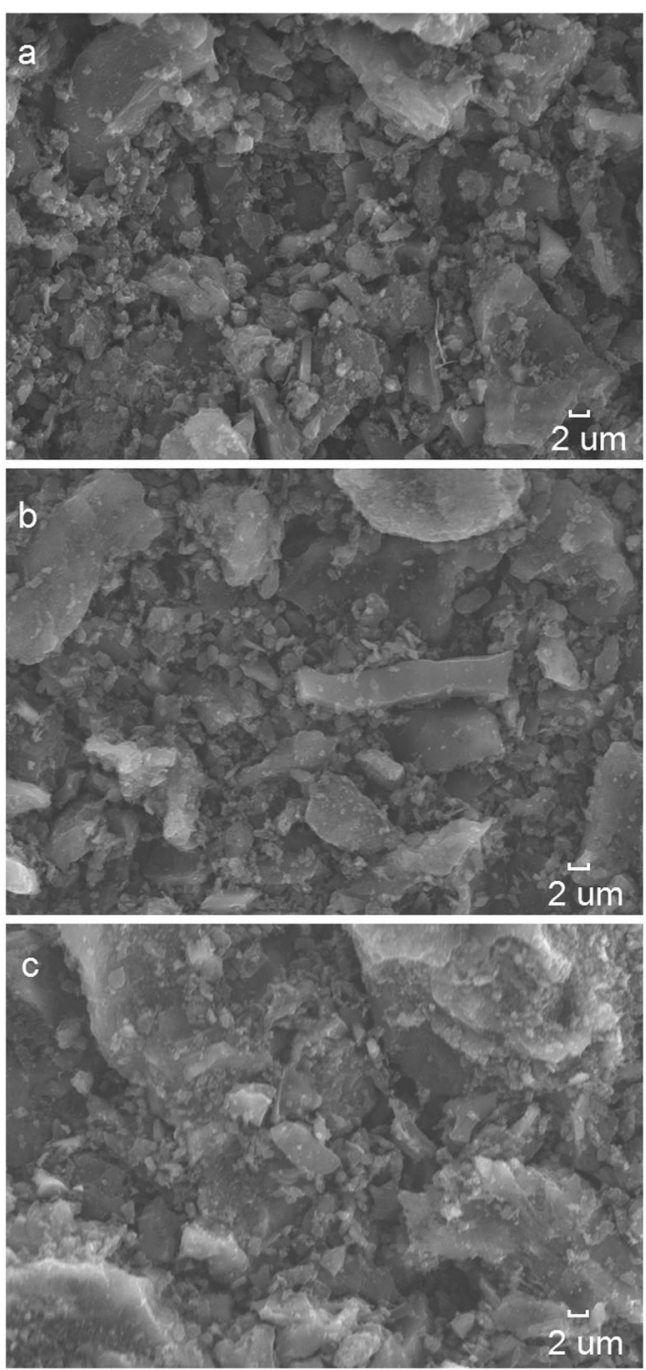

Fig. 4 SEM images of unmodified activated carbon (a), after $30 \mathrm{~min}$ (b) and $60 \mathrm{~min}$ of ozone exposure (c) 

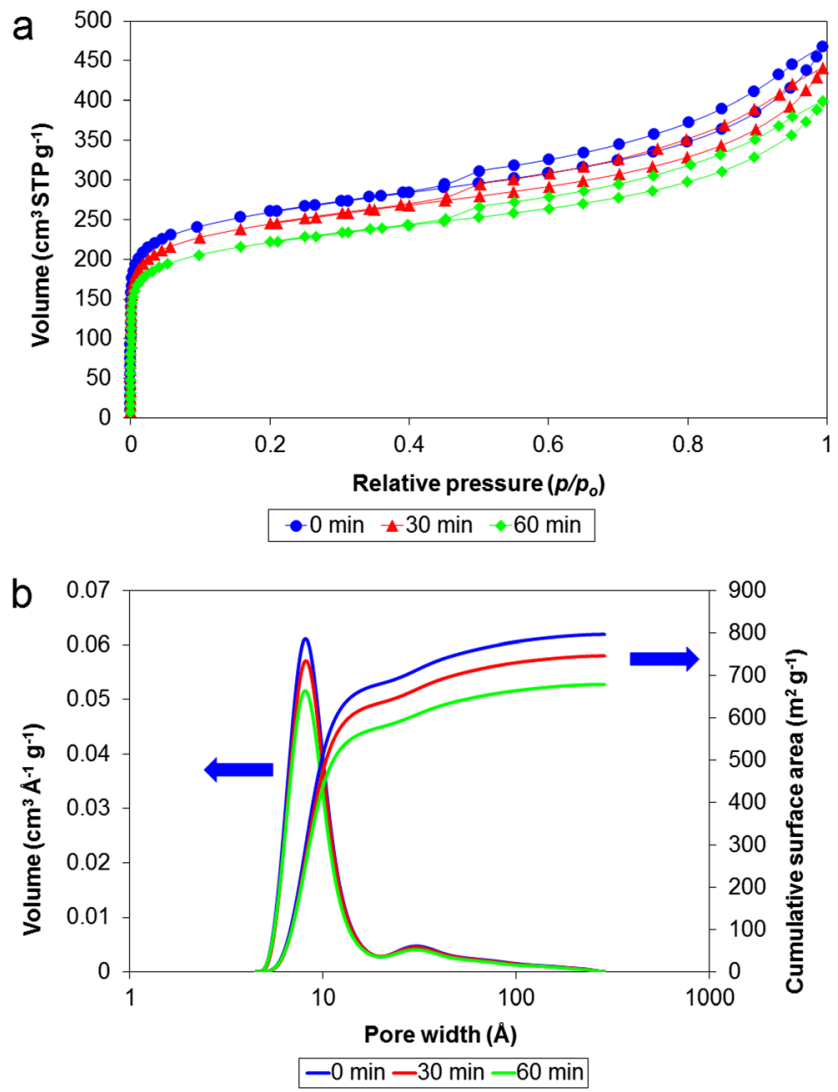

Fig. 5 Nitrogen adsorption/desorption isotherms at $77 \mathrm{~K}$ (a); pore size distribution (b)

ozone (see Fig. 2). The bands at around 1165 and $1220 \mathrm{~cm}^{-1}$ are associated with the stretching modes of the $\mathrm{C}-\mathrm{O}$ species which can be found in acids, esters, or ethers. Moving on towards the higher value of wave number, the band at around $1384 \mathrm{~cm}^{-1}$ can be seen, which might indicate the appearance of nitrogen species $\mathrm{C}-\mathrm{N}$ being incorporated into the carbon structure. These results match those of elemental analysis (Table 1) in which the nitrogen content slightly increases as ozonation time goes. The FTIR spectra also show absorption bands at 1584 and $1725 \mathrm{~cm}^{-1}$, which can be assigned to the stretching vibration of $\mathrm{C}=\mathrm{O}$ in quinone-like structures and the carboxylic acid groups $(-\mathrm{COOH})$, respectively. Therefore, it can be assumed that due to the quick faradaic reactions (quinone/hydroquinone redox couple), the capacitance value should increase as ozonation time rises. It should be mentioned that the bands at 2850 and $2920 \mathrm{~cm}^{-1}$ (present at the surface of unmodified carbon) disappear entirely during ozone oxidation. The regarded bands are assigned to the stretching modes of $\mathrm{C}-\mathrm{H}$ bonds. This allows stating that the process of carbon modification causes the decrease of $\mathrm{C}-\mathrm{H}$ species and simultaneously creates carboxylic moieties. The above-mentioned hypothesis is supported by the fact that the intensity of band at 2325$2368 \mathrm{~cm}^{-1}$ ascribed to the $-\mathrm{OH}$ bond pertaining to carboxylic groups increases as ozonation time goes up [30-33]. The intensities of all the aforementioned bands increase with the
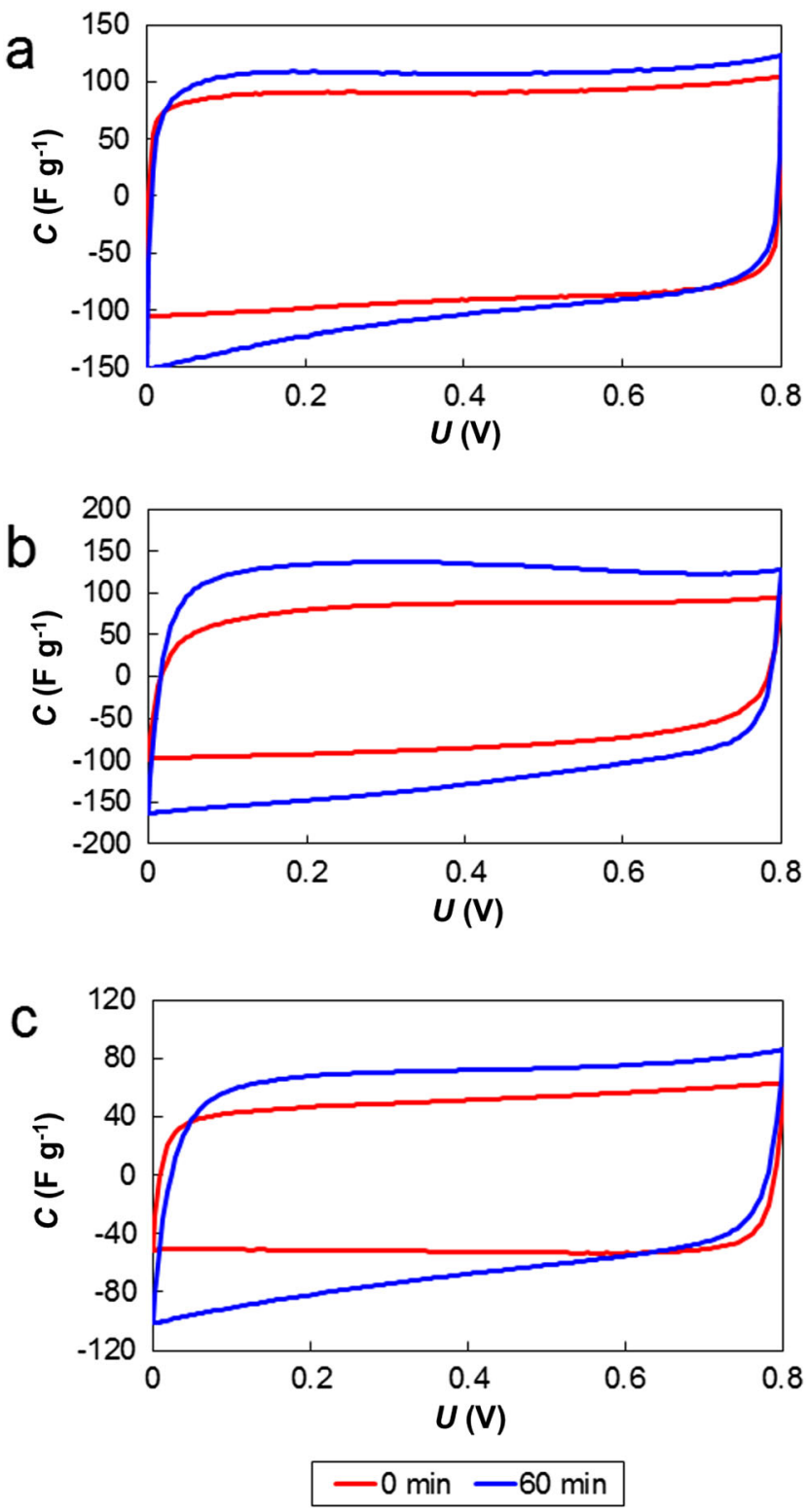

Fig. 6 Cyclic voltammetry at $10 \mathrm{mV} \mathrm{s}^{-1}$ for $1 \mathrm{M} \mathrm{H}_{2} \mathrm{SO}_{4}($ a), $6 \mathrm{M} \mathrm{KOH}$ (b), $1 \mathrm{M} \mathrm{Na}_{2} \mathrm{SO}_{4}$ (c) (two-electrode cell)

Table 2 Capacitance values calculated from cyclic voltammetry at $10 \mathrm{mV} \mathrm{s}^{-1}$ (two-electrode cell)

\begin{tabular}{ccll}
\hline Time of ozone exposure & $\begin{array}{l}C\left(\mathrm{~F} \mathrm{~g}^{-1}\right) \\
1 \mathrm{M} \mathrm{H}_{2} \mathrm{SO}_{4}\end{array}$ & $\begin{array}{l}C\left(\mathrm{~F} \mathrm{~g}^{-1}\right) \\
6 \mathrm{M} \mathrm{KOH}\end{array}$ & $\begin{array}{l}C\left(\mathrm{~F} \mathrm{~g}^{-1}\right) \\
1 \mathrm{M} \mathrm{Na}_{2} \mathrm{SO}_{4}\end{array}$ \\
\hline $0 \mathrm{~min}$ & 91 & 79 & 40 \\
$15 \mathrm{~min}$ & 101 & 89 & 52 \\
$30 \mathrm{~min}$ & 100 & 99 & 61 \\
$60 \mathrm{~min}$ & 106 & 123 & 67 \\
$120 \mathrm{~min}$ & 100 & 110 & 65 \\
$240 \mathrm{~min}$ & 90 & 112 & 54 \\
\hline
\end{tabular}



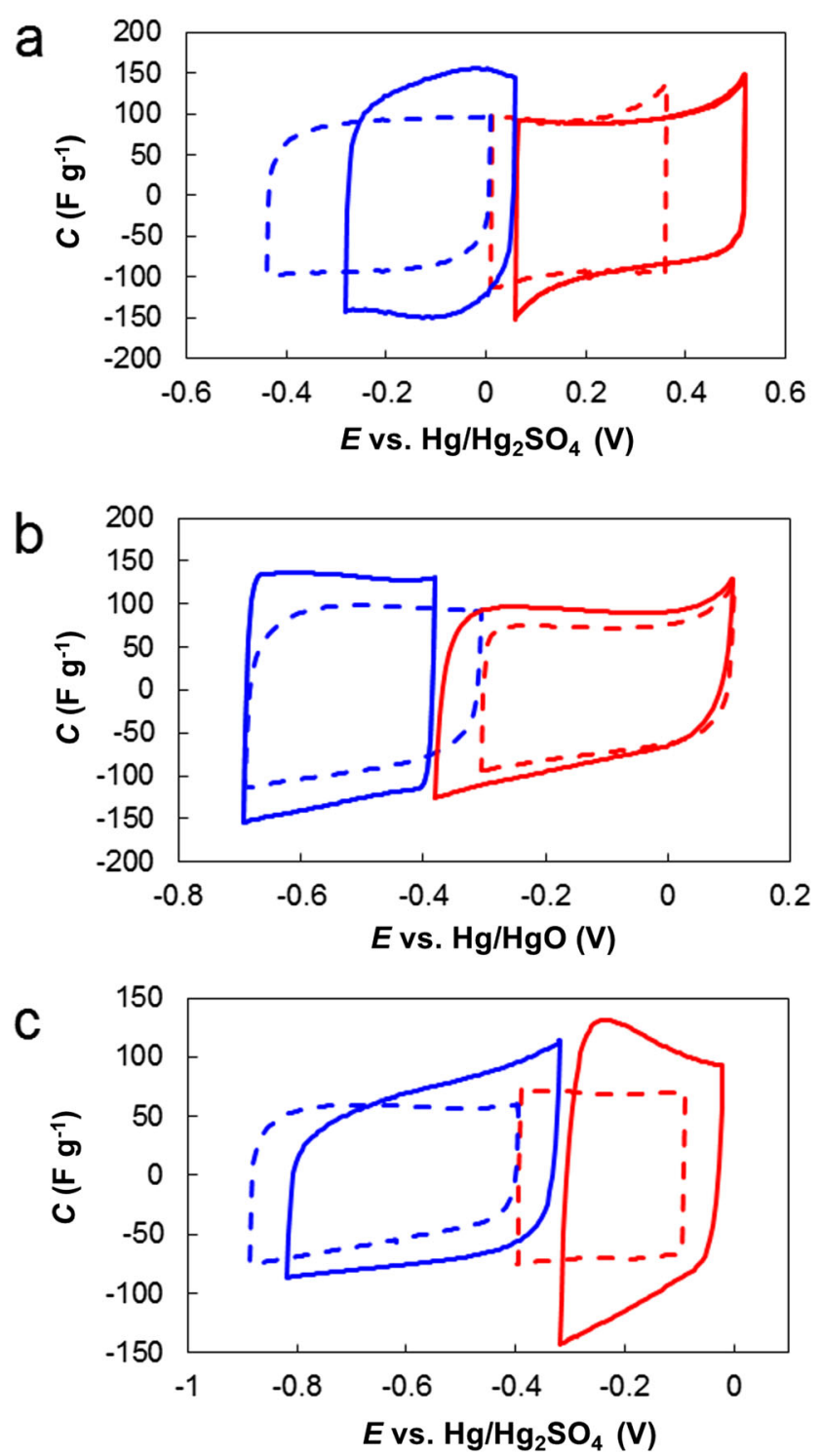

Fig. 7 Cyclic voltammetry at $5 \mathrm{mV} \mathrm{s}^{-1}$ for $1 \mathrm{M} \mathrm{H}_{2} \mathrm{SO}_{4}$ (a), $6 \mathrm{M} \mathrm{KOH}(\mathbf{b})$, $1 \mathrm{M} \mathrm{Na}_{2} \mathrm{SO}_{4}$ (c) for the positive (red line) and the negative electrode (blue line). The raw material was assigned by the dotted line and modified over $60 \mathrm{~min}$ by the solid line

surface oxygen and nitrogen concentration, which is in accordance with the results of elemental analysis (Table 1). In addition, due to changes in oxygen species present on carbon surface, there are more $\mathrm{sp}^{3}$ sites, which is consistent with the Raman spectroscopy investigations.

The results from thermogravimetric analysis are shown as the weight loss as a function of temperature (Fig. 3a) and as derivative curves (Fig. 3b). After being modified, the samples lose more mass. The peak at $100-120^{\circ} \mathrm{C}$ is associated with elimination of water. It can be assumed that the carbon materials after ozone treatment are more hydrophilic. Moreover, the data shows a significant release of carbon oxides as a result of oxygen species present on the carbon surface being decomposed. The peak between 200 and $300{ }^{\circ} \mathrm{C}$ is assigned to the carbon dioxide formation. Carbon dioxide is released after carboxylic groups decompose. In addition, carbon monoxide is formed between 500 and $800{ }^{\circ} \mathrm{C}$ as a result of carboxylic anhydrides and lactone and carbonyl groups being decomposed. The results indicate that the process of ozonation is a highly efficient method of modifying the carbon surface [34-36].

The morphology of the modified and unmodified samples were observed by scanning electron microscopy (Fig. 4), whereas the physisorption of nitrogen method at $77 \mathrm{~K}$ was applied to determine the BET surface (Fig. 5a) and pore size distribution (Fig. 5b). As seen from the SEM images, activated carbon changed its morphology after being treated with ozone. Because of the intensive interactions between the ozone and carbon surface, some small particles likely being the result of carbon decomposition are observed. The number of these elements increases as ozonation time rises (see Fig. 4b, c).

Based on the obtained isotherms, it can be concluded that all isotherms are characteristic of microporous materials with a small number of mesopores. Mesopores are responsible for transporting ions into micropores. The pore size distribution of carbons (PSD, calculated by NLDFT method with heterogeneous surface model using SAIEUS Program, ver. 1.02, by J. Jagiello) [37] confirmed the unimodal PSD profile with the highest contribution of micropores, as shown in Fig. 5b. Moreover, the volume of micropores decreases as ozonation time rises. Unmodified activated carbon has a better developed specific surface area $796 \mathrm{~m}^{2} \mathrm{~g}^{-1}$ than the ozonated one. The calculated specific surface area for carbon modified over 30 , 60 , and $120 \mathrm{~min}$ were 746,679 , and $705 \mathrm{~m}^{2} \mathrm{~g}^{-1}$, respectively. It
Table 3 Capacitance $\left(\mathrm{F} \mathrm{g}^{-1}\right)$ values calculated from cyclic voltammetry at $5 \mathrm{mV} \mathrm{s}^{-1}$ (threeelectrode cell)

\begin{tabular}{|c|c|c|c|c|c|c|}
\hline \multirow{2}{*}{$\begin{array}{l}\text { Time of ozone } \\
\text { exposure }\end{array}$} & \multicolumn{2}{|c|}{$1 \mathrm{M} \mathrm{H}_{2} \mathrm{SO}_{4}$} & \multicolumn{2}{|l|}{$6 \mathrm{M} \mathrm{KOH}$} & \multicolumn{2}{|c|}{$1 \mathrm{M} \mathrm{Na}_{2} \mathrm{SO}_{4}$} \\
\hline & $\begin{array}{l}\text { Negative } \\
\text { electrode }\end{array}$ & $\begin{array}{l}\text { Positive } \\
\text { electrode }\end{array}$ & $\begin{array}{l}\text { Negative } \\
\text { electrode }\end{array}$ & $\begin{array}{l}\text { Positive } \\
\text { electrode }\end{array}$ & $\begin{array}{l}\text { Negative } \\
\text { electrode }\end{array}$ & $\begin{array}{l}\text { Positive } \\
\text { electrode }\end{array}$ \\
\hline $0 \mathrm{~min}$ & 109 & 99 & 87 & 72 & 54 & 68 \\
\hline $15 \mathrm{~min}$ & 103 & 95 & 103 & 73 & 64 & 57 \\
\hline $30 \mathrm{~min}$ & 112 & 82 & 119 & 86 & 84 & 57 \\
\hline $60 \mathrm{~min}$ & 123 & 102 & 130 & 98 & 68 & 101 \\
\hline $120 \mathrm{~min}$ & 115 & 82 & 123 & 102 & 68 & 78 \\
\hline
\end{tabular}


can be concluded that the walls of pores are destroyed after being ozonated. The damaged structure causes the micropores and mesopores to bury. However, the presence of oxygen functionalities hinders nitrogen accessing the micropores and mesopores [38-41].

The electrochemical properties of modified activated carbon were studied in a two-electrode cell in acidic, basic, and neutral solution. Figure 6 shows cyclic voltammograms (CVs) of tested materials at a scan rate equal to $10 \mathrm{mV} \mathrm{s}^{-1}$. The $\mathrm{CV}$ loops were almost rectangular in shape, so it can be stated that the examined materials have good capacitive properties. All the calculated capacitances (expressed per active mass of a single electrode) were summarized in Table 2. Based on the CV measurements, it can be concluded that the ozonation process increases the specific capacitance of electrochemical capacitors. The activated carbon modified for 60 min performed best, because its capacitance increased not only in the acidic electrolytes but also in basic and neutral ones. The highest capacitance was observed for capacitors operated in $6 \mathrm{M} \mathrm{KOH-:}$ its capacitance reached $123 \mathrm{~F} \mathrm{~g}^{-1}$. After all investigated electrolytes were exposed to ozone for $120 \mathrm{~min}$, there was a decrease in specific capacitance. Despite the fact that the surface area decreases during ozonation time, an increase in capacitance was observed. It can be stated that the presence of oxygen functionalities intensifies the wettability of the carbon surface and modifies charge storage properties, which is in accordance with the results of thermogravimetric and FTIR analysis.

Taking into account that two-electrode experiments provide only general characteristics, it is not possible to determine which electrode (negative or positive) is characterized by the higher value of capacitance. The detailed analysis of a single electrode performed in a three-electrode cell reveals important differences in the capacitance of all tested electrolytes. It should be mentioned that these properties strongly depend on the polarity of electrodes. The analysis of single electrodes was presented in Fig 7. It can be concluded that the negative electrode has a higher value of capacitance (Table 3 ). The best results were observed for the supercapacitor operated in $6 \mathrm{M}$ $\mathrm{KOH}$ electrolyte modified over $60 \mathrm{~min}$. The electrochemical and physicochemical measurements indicate that the reversible reactions of quinone/hydroquinone groups could increase capacitance in different electrolytes. The reduction process of quinone depends on the $\mathrm{pH}$ value. At acidic electrolyte, the reduction is a two-electron and two-proton process, but in alkaline $\mathrm{pH}$ the reduction does not bind to exchange the protons. On the other hand, at neutral $\mathrm{pH}$ the reaction can proceed without protons as well as with one proton and two electrons [42]. The extensive studies on kinetics of quinone-like compounds indicate that at low $\mathrm{pH}$ value the reduction process consists of two protonation steps. The protonation reaction following the first electron transfer is slower. Based on the literature data, it can be concluded that when the $\mathrm{pH}$ value is increased the reduction peak is visible at more negative potentials [43]. Moreover, at higher $\mathrm{pH}$ values a much narrower separation peak is observed by many authors, which indicates that the reaction, although thermodynamically less favorable, is much faster kinetically [44]. Therefore, we assume that the electrochemical supercapacitor based on the basic electrolyte exhibits the best performance.

The performance of the capacitor was also examined by electrochemical impedance spectroscopy measurements. The
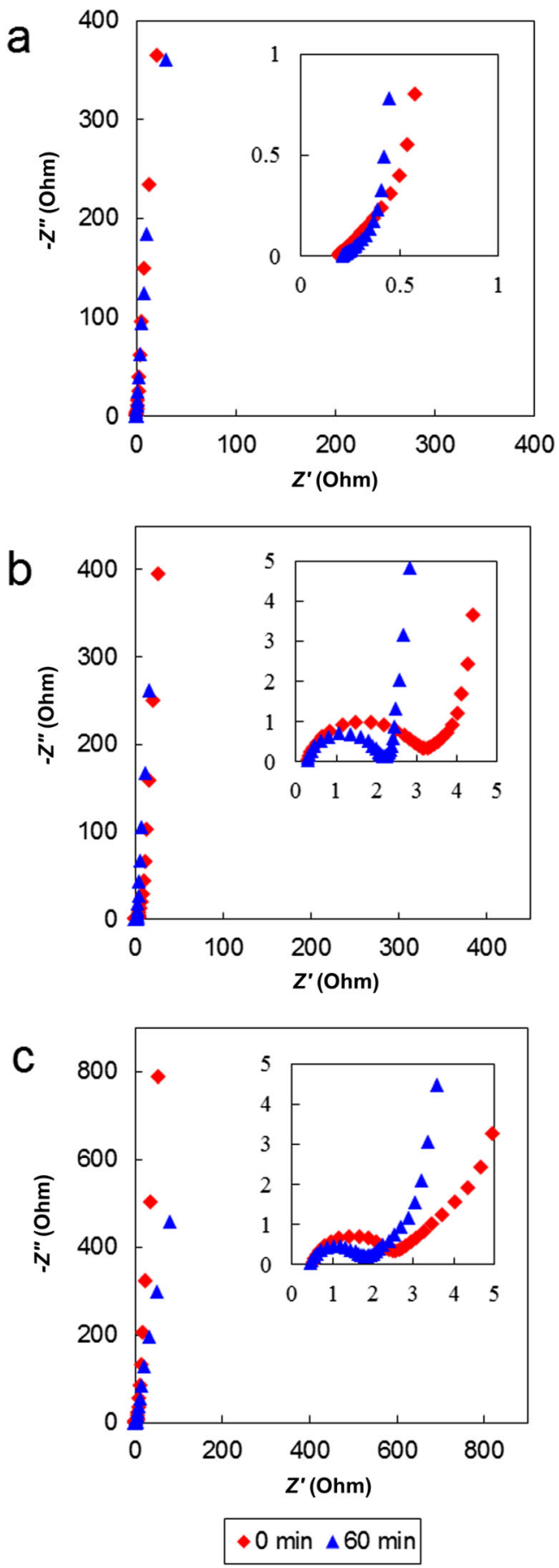

Fig. 8 The electrochemical impedance spectroscopy for $1 \mathrm{M} \mathrm{H}_{2} \mathrm{SO}_{4}(\mathbf{a})$, $6 \mathrm{M} \mathrm{KOH}(\mathbf{b}), 1 \mathrm{M} \mathrm{Na}_{2} \mathrm{SO}_{4}$ (c) 
impedance spectra (the Nyquist plots) are shown in Fig. 8. The obtained results prove that the process of ozonation enhanced the efficiency of the capacitor. Generally, the impedance spectra consist of two parts, the semicircle at high frequency and the straight line at the low-frequency range. Despite the fact that all capacitors (based on the modified and unmodified materials) characterized the comparable value of $\operatorname{ESR}(0.2,0.3$, and $0,45 \Omega$ for acidic, basic, and neutral electrolytes, respectively), the modified samples have lower charge transfer resistance. It should be noted that the supercapacitor based on ozonated carbons operated in $6 \mathrm{M} \mathrm{KOH}$ electrolyte is characterized by lower diffusion resistance. However, the electrochemical capacitors with ozonated electrodes reach the lower value of imaginary part of impedance. The lower value of the imaginary part of impedance indicates higher capacitance of systems. The highest value of capacitance was observed for the capacitor based on the material modified over $60 \mathrm{~min}$ and operated in $6 \mathrm{M} \mathrm{KOH}$, because its capacitance reached $123 \mathrm{~F} \mathrm{~g}^{-1}(1 \mathrm{mHz})$.

In order to provide a more detailed characterization, the value of the imaginary part of capacitance $C^{\prime \prime}$ was calculated. Figure 9 presents the $C^{\prime \prime}$ versus frequency. The imaginary part
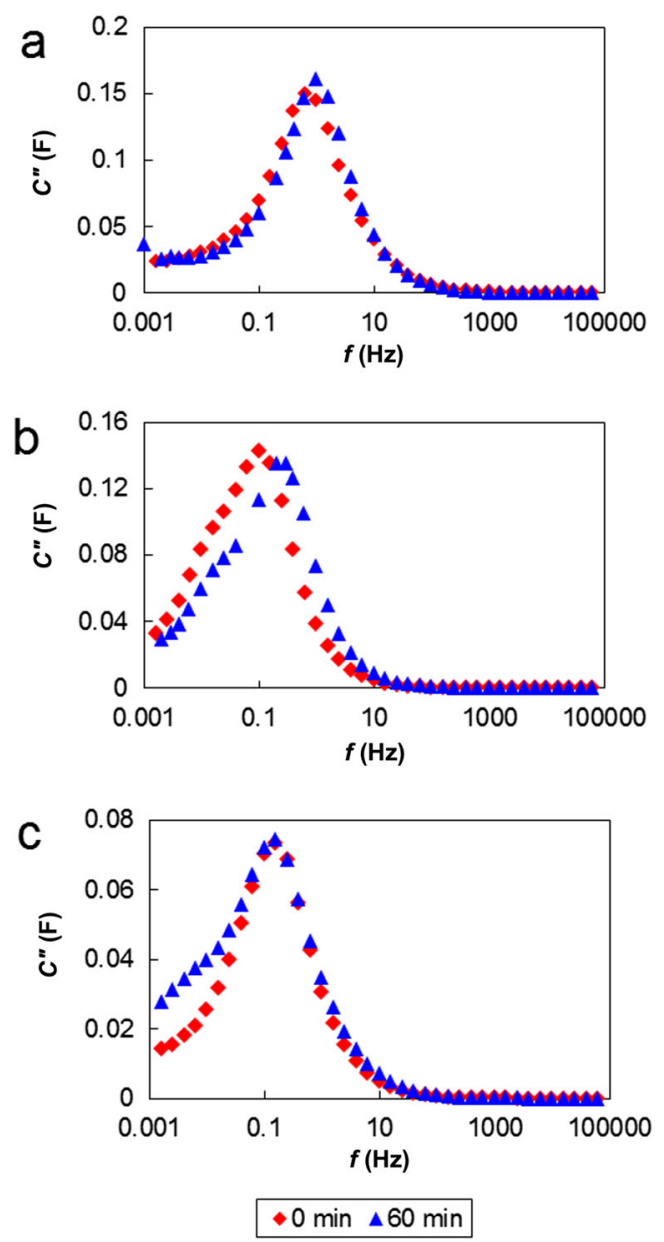

Fig. 9 The relation between the imaginary part of impedance versus frequency for $1 \mathrm{M} \mathrm{H}_{2} \mathrm{SO}_{4}$ (a), $6 \mathrm{M} \mathrm{KOH}(\mathbf{b}), 1 \mathrm{M} \mathrm{Na}_{2} \mathrm{SO}_{4}$ (c) of capacitance has a maximum at a frequency, determining the time constant. Time constant is the amount of time required to charge the capacitor. Based on careful analysis, it can be stated that the time constant of capacitors based on the modified electrodes and operated in $1 \mathrm{M} \mathrm{H}_{2} \mathrm{SO}_{4}$ and $6 \mathrm{M} \mathrm{KOH}$ is smaller than that of the untreated one, i.e., 1.0 and $3.4 \mathrm{~s}$, respectively. It can be concluded that the capacitor with ozonated electrodes is able to deliver its stored energy faster than the one based on the unmodified electrodes, taking into account that an electrochemical capacitor based on the modified electrodes over $60 \mathrm{~min}$ and operated in neutral electrolyte has a higher value of capacitance and it is able to deliver energy at the same time as the capacitor with untreated electrodes, i.e., $6.25 \mathrm{~s}$ [45].

\section{Conclusions}

To summarize, the presented studies show that ozonation process has a beneficial impact on the chemical and physical properties of activated carbon. After being modified, the carbon material has more oxygen and nitrogen functionalities resulting in the higher content in $\mathrm{sp}^{3}$ sites. Electrochemical measurements showed that ozone-treated carbon can be recognized as a very attractive material to construct the electrochemical capacitor. AC and DC methods revealed an increase in specific capacitance due to the ozonation process. The capacitors based on carbon were ozonated for $60 \mathrm{~min}$ and had the best performance. Moreover, the highest capacitance was observed for the capacitor operating in $6 \mathrm{M} \mathrm{KOH}$. We assume that the reduction process of quinone-like groups is much faster kinetically and occurs in more negative potential in basic electrolytes. It should be noted that the negative electrode has a higher value of capacitance - this is very important to construct the electrochemical capacitor with asymmetric electrodes.

Acknowledgments The authors would like to gratefully acknowledge the financial support from the National Science Centre of Poland, grant no. DEC-2013/10/E/ST5/00719.

Open Access This article is distributed under the terms of the Creative Commons Attribution 4.0 International License (http:// creativecommons.org/licenses/by/4.0/), which permits unrestricted use, distribution, and reproduction in any medium, provided you give appropriate credit to the original author(s) and the source, provide a link to the Creative Commons license, and indicate if changes were made.

\section{References}

1. Álvarez PM, García-Araya JF, Beltrán FJ, Masa FJ, Medina F (2005) Ozonation of activated carbons: effect on the adsorption of selected phenolic compounds from aqueous solutions. J Colloid Interface Sci 283:503-512

2. Wang YX, Ngo HH, Guo WS (2015) Preparation of a specific bamboo based activated carbon and its application for ciprofloxacin removal. Sci Total Environ 533:32-39 
3. Frackowiak E, Béguin F (2001) Carbon materials for the electrochemical storage of energy in capacitors. Carbon 39:937-950

4. Lota K, Acznik I, Sierczynska A, Lota G (2016) The capacitance properties of activated carbon obtained from chitosan as the electrode material for electrochemical capacitors. Mater Lett 173:72-75

5. Lin CC, Yen CC (2007) RF oxygen plasma treatment of activated carbon electrodes for electrochemical capacitors. J Appl Electrochem 37:813-817

6. Milczarek G, Ciszewski A, Stepniak I (2011) Oxygen-doped activated carbon fiber cloth as electrode material for electrochemical capacitor. J Power Sources 196:7882-7885

7. Zhong C, Gong S, Jin L, Li P, Cao Q (2015) Preparation of nitrogen-doped pitch-based carbon materials for supercapacitors. Mater Lett 156:1-6

8. Zhao Y, Liu M, Deng X, Miao L, Tripathi PK, Ma X, Zhu D, Xu Z, Hao Z, Gan L (2015) Nitrogen-functionalized microporous carbon nanoparticles for high performance supercapacitor electrode. Electrochim Acta 153:448-455

9. Zhu D, Wang Y, Gan L, Liu M, Cheng K, Zhao Y, Deng X, Sun D (2015) Nitrogen-containing carbon microspheres for supercapacitor electrodes. Electrochim Acta 158:166-174

10. Lota G, Tyczkowski J, Makowski P, Balcerzak J, Lota K, Acznik I, Peziak-Kowalska D, Kolanowski Ł (2016) The modified activated carbon treated with a low-temperature iodine plasma used as electrode material for electrochemical capacitors. Mater Lett 175:96-100

11. Valdés H, Sánchez-Polo M, Rivera-Utrilla J, Zaror CA (2002) Effect of ozone treatment on surface properties of activated carbon. Langmuir 18:2111-2116

12. Sutherland I, Sheng E, Bradley RH, Freakley PK (1996) Effects of ozone oxidation on carbon black surfaces. J Mater Sci 31:5651-5655

13. Conway BE (1999) Electrochemical supercapacitors. Kluwer Academic/Plenum Publishers, New York

14. Béguin F, Frackowiak E (eds) (2013) Supercapacitors: materials, systems and applications. Wiley-VCH, Weinheim

15. Lota K, Lota G, Sierczynska A, Acznik I (2015) Carbon/polypyrrole composites for electrochemical capacitors. Synth Met 203:44-48

16. Menzel J, Fic K, Meller M, Frackowiak E (2014) The effect of halide ion concentration on capacitor performance. J Appl Electrochem 44:439-445

17. Lota G, Frackowiak E (2009) striking capacitance of carbon/iodide interface. Electrochem Commun 11:87-90

18. Lota G, Fic K, Frackowiak E (2011) Alkali metal iodide/carbon interface as a source of pseudocapacitance. Electrochem Commun 13: 38-41

19. Cho MY, Kim MH, Kim HK, Kim KB, Yoon JR, Roh KC (2014) Electrochemical performance of hybrid supercapacitor fabricated using multi-structured activated carbon. Electrochem Commun 47:5-8

20. Pognon G, Brousse T, Bélanger D (2011) Effect of molecular grafting on the pore size distribution and the double layer capacitance of activated carbon for electrochemical double layer capacitors. Carbon 49:1340-1348

21. Brousse T, Bélanger D, Long JW (2015) To be or not to be pseudocapacitive. J Electrochem Soc 162:A5185-A5189

22. Eskusson J, Jänes A, Kikas A, Matisen L, Lust E (2011) Physical and electrochemical characteristics of supercapacitors based on carbide derived carbon electrodes in aqueous electrolytes. J Power Sources 196:4109-4116

23. Kopczyński K, Milczarek G, Lota G (2016) Polysulphides reversible faradaic reactions in supercapacitor application. Electrochem Commun 68:28-31

24. Lota G, Tyczkowski J, Kapica R, Lota K, Frackowiak E (2010) Carbon materials modified by plasma treatment as electrodes for supercapacitors. J Power Sources 195:7535-7539

25. Pognon G, Brousse T, Demarconnay L, Bélanger D (2011) Performance and stability of electrochemical capacitor based on anthraquinone modified activated carbon. J Power Sources 196: 4117-4122

26. Ferrari AC, Robertson J (2000) Interpretation of Raman spectra of disordered and amorphous carbon. Phys Rev B 61:14095-14107

27. Roh JS (2008) Structural study of the activated carbon fiber using laser Raman spectroscopy. Carbohydr Lett 9:127-130

28. Lu W, Liu M, Miao L, Zhu D, Wang X, Duan H, Wang Z, Li L, Xu Z, Gan L, Chen L (2016) Nitrogen-containing ultramicroporous carbon nanospheres for high performance supercapacitor electrodes. Electrochim Acta 205:132-141

29. Ferrari AC (2007) Raman spectroscopy of grapheme and graphite: disorder, electron-phonon coupling, doping and nanodiabatic effects. Solid State Commun 143:47-57

30. Kim JH, Min BG (2010) Functionalization of multi-walled carbon nanotube by treatment with dry ozone gas for the enhanced dispersion and adhesion in polymeric composites. Carbohydr Lett 11: 298-303

31. Biniak S, Szymański G, Siedlewski J, Świątkowski A (1997) The characterization of activated carbons with oxygen and nitrogen surface groups. Carbon 35:1799-1810

32. Pradhan BK, Sandle NK (1999) Effect of different oxidizing agent treatments on the surface properties of activated carbons. Carbon 37:1323-1332

33. Mawhinney DB, Yates JT Jr (2001) FTIR study of the oxidation of amorphous carbon by ozone at $300 \mathrm{~K}$-direct $\mathrm{COOH}$ formation. Carbon 39:1167-1173

34. Liang S, Li G, Tian R (2016) Multi-walled carbon nanotubes functionalized with a ultrahigh fraction of carboxyl and hydroxyl groups by ultrasound-assisted oxidation. J Mater Sci 51:3513-3524

35. Metzinger T, Hüttinger KJ (1997) Investigations on the crosslinking of binder pitch matrix of carbon bodies with molecular oxygen-part I. Chemistry and reactions between pitch and oxygen. Carbon 35:885-892

36. Goscianska J, Olejnik A, Nowak I, Marciniak M, Pietrzak R (2016) Stability analysis of functionalized mesoporous carbon materials in aqueous solution. Chem Eng J 290:209-219

37. Jagiello J, Olivier JP (2013) 2D-NLDFT adsorption models for carbon slit-shaped pores with surface energetical heterogeneity and geometrical corrugation. Carbon 55:70-80

38. Sing KSW, Everett DH, Haul RAW, Moscou L, Pierotti RA, Rouquerol J, Siemieniewska T (1985) Reporting physisorption data for gas/solid systems with special reference to the determination of surface area and porosity. Pure Appl Chem 57:603-619

39. Liu M, Qian J, Zhao Y, Zhu D, Gan L, Chen L (2015) Core-shell ultramicroporous@microporous carbon nanospheres as advanced supercapacitor electrodes. J Mater Chem A 3:11517-11526

40. Zhao Y, Liu M, Gan L, Ma X, Zhu D, Xu Z, Chen L (2014) Ultramicroporous carbon nanoparticles for the high-performance electrical double-layer capacitor electrode. Energy Fuel 28:1561-1568

41. Tripathi PK, Liu M, Zhao Y, Ma X, Gan L, Noonan O, Yu C (2014) Enlargement of uniform micropores in hierarchically ordered micro-mesoporous carbon for high level decontamination of bisphenol A. J Mater Chem A 2:8534-8544

42. Guin PS, Das S, Mandal PC (2011) Electrochemical reduction of quinones in different media: a review. Int J Electrochem 2011:1-22

43. Shim YB, Park SM (1997) Spectroelectrochemical studies of pbenzoquinone reduction in aqueous media. J Electroanal Chem 425:201-207

44. Quan M, Sanchez D, Wasylkiw MF, Smith DK (2007) Voltammetry of quinones in unbuffered aqueous solution: reassessing the roles of proton transfer and hydrogen bonding in the aqueous electrochemistry of quinones. J Am Chem Soc 129:12847-12856

45. Taberna PL, Simon P, Fauvarque JF (2003) Electrochemical characteristics and impedance spectroscopy studies of carbon-carbon supercapacitors. J Electrochem Soc 150:A292-A300 